\title{
Analisis Penerapan Business Model Canvas Pada Koperasi Syariah
}

\author{
Intan Nurrachmi, Setiawan
}

Universitas Islam Bandung, Politeknik Negeri Bandung

intannurrachmi@gmail.com, setiawan@polban.ac.id

\section{Article Info}

Article history:

Received Oct19th, 2020

Revised Oct 30th, 2020

Accepted Nov 5th, 2020

\section{Keyword:}

Business Models,

Sharia Cooperatives,

Business Models Canvas

\begin{abstract}
Islamic cooperatives are business entities that have the purpose of profit and social benefits, it is necessary to support all parties, both directly and indirectly, so that the role of Islamic cooperatives in improving the economic welfare of the community can be realized with financing products that are very beneficial for the Islamic cooperative as well as for the customers. This study aims to analyze the Sharia Cooperative business model using Business Model Canvas. The research method used is descriptive method with a case study approach. While the stages are data collection, data processing and making conclusions. Koperasi Syariah KSBM tries its best to provide various product services to consumers. How to socialize products and establish friendships made a form of whatsapp groups. The profit gained by KSBM is from product sales, profit sharing from savings and loans as well as from services. The KSBM partnership was established with BRI Syariah, Post Office and Samsat.
\end{abstract}

Copyright@ 2020 Program Studi Ekonomi Syariah Universitas Yudharta Pasuruan All rights reserved.

DOI: https://doi.org/10.35891/ml.v12i1.1896

\section{Corresponding Author:}

Intan Nurrachmi, student of the Islamic University of Bandung

Email: intannurrachmi@gmail.com 


\section{A. Pendahuluan}

Keberadaan pasar modern (minimarket, hypermarket dan supermarket) menurut beberapa kalangan menjadi penyebab tersudutkannya kondisi pasar tradisional terutama yang berlokasi di perkotaan. Hasil penelitian AC Nielsen, pada tahun 2005 pasar tradisional di Indonesia mengalami penyusutan sebesar 8\%, sedangkan disisi lain pasar modern mengalami pertumbuhan $31,4 \%$ per tahunnya (Jati, 2012). Sejalan dengan hasil penelitian tersebut PT Solusi Dinamika Manajemen bersama Kementerian Koperasi dan UKM (Kemenkop UKM) mengungkapkan hasil kajiannya pada tahun 2005 yang menyatakan bahwa eksistensi pasar modern telah terancam dengan hadirnya pasar modern tersebut. Semua pasar modern tersebut dimiliki atau dikuasai oleh perusahaanperusahaan swasta, dengan kata lain perusahaan swasta lebih mendominasi dalam hal pemasaran di Indonesia (Nizar, 2016).

Sekarang sasaran dari pasar modern bukan lagi hanya penduduk yang berpendapatan menengah atau menengah ke atas, namun sudah masuk ke dalam segmen masyarakat yang berpendapatan menengah ke bawah dengan cara membuka minimarket sampai ke tingkat kecamatan bahkan kelurahan. Sebagai contoh telah banyak berdirinya gerai-gerai seperti alfamart, indomart dan yomart dimana gerai-gerai tersebut termasuk bentuk dari pasar modern (Setiawan, 2016).

Kehadiran pasar modern tersebut sedikit banyak telah mempengaruhi gaya hidup masyarakat yang lebih memilih brand (produk, supermarket, minimarket, dan sebagainya) dibandingkan membeli produk dari pasar tradisional atau toko-toko kecil yang berada di dekat rumahnya. hal ini terjadi karena masyarakat menganggap pelayanan dan ketersediaan barang di Supermarket atau minimarket lebih baik dan lebih memadai dibandingkan dengan pasar tradisional atau toko-toko kecil lainnya.

Keadaan tersebut menuntut bagi perkoperasian di Indonesia yang salah satu perannya adalah mewujudkan dan mengembangkan perekonomian nasional yang merupakan usaha bersama berdasarkan azas kekeluargaan dan demokrasi ekonomi. Dalam hal ini koperasi harus menjadi sebuah solusi agar masyarakat tidak berperilaku konsumtif namun dituntut untuk menjadi pribadi yang produktif. Apabila masyarakat menyadari betapa besar manfaat koperasi akan menjadi kekuatan karena persatuan dalam kekeluargaan sekaligus akan mengembangkan perekonomian dan kesejahteraan nasional.

Kementrian Koperasi dan Usaha Kecil Menengah mengungkapkan bahwa Indonesia mencatatkan sebagai negara dengan jumlah koperasi terbanyak di dunia. Sesuai data dari Kemenkop UKM Per Desember 2019 tercatat bahwa jumlah koperasi di Indonesia mencapai 158.809 koperasi. Meskipun begitu dalam laporan statistiknya Kemenkop UKM menyampaikan bahwa data ini masih sangat sementara, mungkin jumlahnya lebih banyak dari pada itu. Dari 158.809 koperasi tersebut terdiri dari 123.048 koperasi yang aktif dan 35.761 koperasi yang tidak aktif. Adapun jumlah koperasi itu tersebar di 34 Provinsi di seluruh Indonesia dengan keseluruhan jumlah anggotanya mencapai 22,46 Juta anggota (Www.Depkop.Go.Id, 2018).

Koperasi Syariah merupakan bagian dari perkoperasian di Indonesia yang dalam praktiknya berlandaskan tuntunan Alqur'an dan hadis. Meskipun terkadang masih 
dipandang sebelah mata, namun para pelaku koperasi Syariah sangat optimis dalam menghadapi berbagai tantangan ekonomi yang ada. Apalagi diprediksikan Indonesia akan dijadikan sebagai kiblatnya perekonomian Syariah dunia. Hal ini disampaikan pula oleh Kementerian Koperasi dan UKM (Kemenkop UKM), bahwa koperasi syariah ataupun baitul maal wa tamwil (BMT) mempunyai peran penting dalam mengambil bagian untuk mewujudkan target pada tahun 2024 indonesia harus menjadi basis perekonomian dan keuangan Syariah dunia. Hal ini didasarkan pada alasan bahwa jumlah koperasi Syariah dan BMT pada tahun 2019 lebih dari 5.000 unit yang menunjukkan peningkatan jumlah yang signifikan. Selain itu mengingat jumlah penduduk muslim di Indonesia merupakan yang terbesar di dunia, ini juga merupakan peluang bagi koperasi Syariah untuk bisa berkiprah dan memperbaiki performanya, serta dapat menyelesaikan persoalan-persoalan internal yang sering dihadapi koperasi Syariah. Harus ada usaha supaya kepercayaan masyarakat meningkat, memperbaiki sumber daya manusia (SDM), memperbaiki permodalan, kepatuhan kepada Syariah, penggunaan teknologi serta peningkatan inovasi produk.

Untuk mencapai semua itu tentunya diperlukan perencanaan yang matang. Karena koperasi Syariah merupakan juga bagian dari bisnis, maka diperlukan perancanaan bisnis yang matang. Dalam mengevaluasi perencanaan bisnis atau bisnis yang sedang dijalani diperlukan acuan yang jelas dan utuh terkait model bisnis. Menurut Giorgetti model bisnis adalah model referensi yang menjadi sebuah dasar bagi sebuah sistem jenis (type) baru yang mempunyai keunggulan dibandingkan pendekatan sebelumnya (Ghulam, 2016).

Penggunaan metode model bisnis kanvas pada lembaga keuangan syariah yaitu koperasi syariah dirasa penting untuk mengoreksi suatu kemungkinan tentang adanya kesalahan konsep atau perlunya perbaikan dalam proses menjalankan model bisnis, karena koperasi syariah merupakan entitas bisnis yang memiliki tujuan profit dan social benefits. Muslich menyatakan bahwa tercapainya tujuan profit dan sosial dari suatu kegiatan bisnis, secara ideal perlu adanya dukungan semua pihak, baik secara langsung ataupun tidak langsung memberikan jasa dalam meraih keuntungan bisnis secara layak (Suparmin, 2019). Sehingga, peran Koperasi syariah dalam meningkatkan kesejahteraan ekonomi masyarakat sangat penting dengan adanya produk pembiayaan yang sangat menguntungkan bagi pihak koperasi syariah juga bagi para nasabah. Berdasarkan hal tersebut maka yang menjadi pokok permasalah dalam penelitian ini adalah "Bagaimana menganalisa model bisnis Koperasi Syariah dengan menggunakan Business Model Canvas?".

\section{B. Kajian Teori}

\section{Koperasi Syariah}

Para ahli telah menjelaskan tentang pengertian koperasi Syariah, antara lain (Anggraini \& Oliver, 2019): 
a. Ahmad Ifham, menjelaskan yang dimaksud koperasi syariah adalah aktivitas koperasi yang meliputi semua kegiatan usaha yang halal, baik, bermanfaat, serta menguntungkan dengan sistem bagi hasil, dan tidak mengandung riba.

b. Soemitra, memaparkan pengertian koperasi syariah adalah suatu lembaga keuangan mikro yang dioperasikan dengan sistem bagi hasil, untuk menumbuhkembangkan usaha mikro dan kecil semua anggotanya sehingga dapat mengangkat derajat dan martabat serta membela kepentingan kaum fakir miskin.

c. Nur S. Buchori, berpendapat yang dimaksud koperasi syariah adalah jenis koperasi yang tujuannya mensejahterakan sosial ekonomi para anggotanya sesuai norma dan moral Islam serta berguna dalam menciptakan persaudaraan dan keadilan yang sesuai dengan prinsip-prinsip syariat Islam.

d. Kementrian Koperasi UKM RI tahun 2009 pasal 1, koperasi syariah adalah suatu bentuk koperasi yang segala kegiatan usahanya bergerak pada bidang pembiayaan, simpanan, sesuai dengan pola bagi hasil (Syariah), dan investasi.

Dari beberapa pengertian tersebut dirangkum bahwa koperasi syariah merupakan koperasi yang usaha-usahanya menerapkan prinsip-prinsip syariah. Maka apabila koperasi Syariah memiliki kegiatan usaha produktif seperti simpanan atau pinjaman, maka koperasi syariah tidak dibenarkan berusaha di bidang-bidang yang ada di dalamnya unsur-unsur riba, maysir, dan gharar. Di samping itu, koperasi syariah boleh melakukan transaksi-transaksi yang merupakan keturunan-keturunan (derivative) dari unsur-unsur tersebut sebagaimana juga berlaku bagi lembaga keuangan syariah lainnya.

Menurut Marwick tujuan koperasi syariah adalah agar terjadi peningkatan kesejahteraan anggotanya dan kesejahteraan masyarakat dan turut serta membangun tingkat perekonomian Bangsa Indonsia berlandaskan syariah Islam (Marwick, 2006). Sedangkan menurut Fachruddin sebagaimana dikutip Suhendi, tujuan koperasi dilihat dari segi fungsinya dapat dibagi menjadi tiga yaitu: Pertama. Koperasi Produksi, merupakan suatu koperasi yang memproduksi barang-barang yang bahan-bahannya berasal dari anggota koperasi; Kedua. Koperasi konsumsi, merupakan suatu koperasi yang melakukan pembelian barang-barang untuk memenuhi kebutuhan para anggotanya; dan Ketiga. Koperasi kredit, merupakan suatu koperasi yang memberikan pertolongan berupa dana usaha kepada anggota-anggotanya yang membutuhkan bantuan modal dan untuk pelunasannya dengan cara dicicil (Herdiana, 2013). Sedangkan Menurut Dusuki dan Abdullah, tujuan koperasi syariah harus sesuai dengan Maqashid Syariah yang fungsinya adalah untuk melakukan dua hal penting, yaitu memberikan manfaat (manfaah) dan mencegah kerusakan atau cedera (madarrah) (Dusuki \& Abdullah, 2007).

Menurut Buchori tujuan koperasi syariah, yaitu: Pertama, mensejahterakan kondisi ekonomi anggotanya sesuai ajaran Islam; Kedua, menjalin persaudaraan dan menciptakan keadilan kepada anggotanya; Ketiga, pembagian hasil pendapatan dan kekayaan yang merata kepada semua anggotanya sesuai dengan tingkat kontribusinya; Keempat, kebebasan pribadi dalam kemaslahatan sosial; Kelima, meningkatkan 
kesejahteraan khususnya para anggotanya dan kesejahteraan masyarakat pada umumnya dan turut serta membangun tingkat perekonomian Bangsa berlandaskan syariah Islam (Efendi \& Bakhri, 2018).

Di Indonesia mulai terbentuknya koperasi Syariah dilandasi oleh Keputusan Menteri (Kepmen) Nomor 91/Kep/MKUKM/IX/2004 tanggal 10 September 2004 tentang Petunjuk Pelaksanaan Kegiatan Usaha Koperasi Jasa Keuangan Syariah. Berlandaskan Al-Quran dan hadis, Pancasila dan Undang-Undang Dasar Tahun 1945.

Berdirinya koperasi syariah memiliki fungsi serta peran khusus, di antaranya (Efendi \& Bakhri, 2018):

a. Membangun dan mengembangkan potensi secara khusus para anggotanya, dan secara umum masyarakat luas, untuk kesejahteraan sosial dan kesejahteraan ekonominya.

b. Menguatkan kualitas SDM anggota koperasi, agar menjadi lebih amanah, professional (fathanah), konsisten, dan konsekuen (istiqomah) di dalam menerapkan prinsip-prinsip ekonomi Islam dan prinsip-prinsip Syari'ah Islam.

c. Berusaha mewujudkan, mengembangkan dan meningkatkan perekonomian nasional yang merupakan usaha bersama berdasarkan azas kekeluargaan dan demokrasi ekonomi.

d. Sebagai perantara di antara penyumbang dana dengan pengguna dana, sehingga pemanfaatan harta dapat dioptimalkan.

e. Menguatkan kelompok-kelompok anggota, agar mampu bekerjasama melakukan kontrol terhadap koperasi secara efektif dan efisien.

f. Mengembangkan dan memperluas kesempatan dan peluang kerja.

g. Menumbuh-kembangkan usaha-usaha produktif para anggotanya.

\section{Business Model Canvas}

Menurut Kamus Besar Bahasa Indonesia, Bisnis adalah usaha dagang atau usaha komersial di dunia perdagangan. Anoraga dan Soegiastuti sebagaimana dikutif Ahmad Rajafi menyatakan Bisnis adalah Pembelian dan penjualan barang dan jasa (Indonesia, 2019). Arti bisnis menurut Hughes dan Kapoor adalah suatu usaha kegiatan individu yang terorganisasi untuk menghasilkan dan menjual barang dan jasa guna mendapatkan keuntungan dalam memenuhi kebutuhan masyarakat. Sedangkan pengertian bisnis menurut Brown dan Petrello adalah suatu lembaga yang menghasilkan barang dan jasa yang dibutuhkan oleh masyarakat (Ilyas, 2018).

Dari pengertian tersebut, maka dapat disimpulkan bahwa pelaku bisnis atau suatu organisasi melakukan bisnis dalam bentuk a) memproduksi dan atau mendistribusikan barang ataupun jasa, b) mencari keuntungan (profit), dan c) memenuhi keinginan atau kebutuhan konsumen/masyarakat.

Menurut Osterwalder dan Pigneur Business Model Canvas (BMC) adalah sebuah model bisnis gambaran logis mengenai bagaimana sebuah organisasi menciptakan, menghantarkan dan menangkap sebuah nilai. Bisnis model canvas dapat dipergunakan dalam semua bentuk bisnis dengan berbagai sektor usaha untuk mengetahui kekuatan dan kelemahannya. Apabila telah diketahui kekuatan dan 
kelemahan suatu bisnis, maka akan dengan mudah dan cepat dalam menganalisis kebutuhan dan keuntungannya.

Canvas ini membagi business model menjadi 9 buah komponen utama, kesembilan komponen yang ada tersebut adalah Customer Segment (segmentasi pelanggan), Customer Relationship (Hubungan pelanggan), Channel (saluran), Revenue Stream (aliran pendapatan), Value Proposition (proposisi nilai), Key Activities (aktivitas utama), Key Resource (sumber daya utama), Cost Structure (struktur biaya), dan Key Partners (kemitraan utama).

\section{Metode}

Penelitian ini menggunakan metode deskriptif yaitu untuk memperoleh gambaran dan penjelasan dari objek penelitian secara faktual, akurat dan sistematis. Sedangkan pendekatan yang digunakan adalah pendekatan studi kasus yaitu untuk meneliti secara mendalam tentang keadaan atau kejadian (kasus) secara sistematis melalui pengamatan, pengumpulan data, menganalisis informasi, dan pengolahan data dan pelaporan hasilnya. Dalam penelitian ini digunakan model bisnis canvas untuk mengetahui elemen-elemen yang terlibat dalam suatu bisnis sehingga dapat diungkapkan kelemahan atau kelebihan dalam bisnis tersebut. Adapun tekniknya melalui wawancara dan Focus Group Discussion (FGD) yang dilakukan terhadap responden. langkah selanjutnya adalah melakukan analisis SWOT pada masingmasing elemen business model canvas (BMC).

Penelitian ini dilaksanakan di Koperasi Syariah Baitul Mu'min yang berlokasi di Komplek Pasirjati Desa Jati Endah Kecamatan Cilengkrang. Adapun alasan pemilihan lokasi ini adalah karena koperasi ini termasuk koperasi yang belum lama berdiri namun sudah menunjukkan perkembangan yang signifikan baik dari segi jumlah anggota, jumlah modal usaha maupun dari pembagian sisa hasil usahanya.

\section{Hasil dan Pembahasan}

\section{Profil Koperasi Syariah Baitul Mu'min (KSBM)}

KSBM didirikan pada tanggal 24 Desember 2015 dan berada dibawah naungan Dewan Kemakmuran Masjid (DKM) Masjid Baitul Mu'min Bandung. KSBM didirikan untuk mewujudkan misi DKM Baitul Mu'min yakni sebagai wadah bermuamalah jama'ah, yang terangkum dalam motto DKM Baitul Mu'min, yakni Makmur Masjidnya, Sejahtera Jama'ahnya. Berdirinya KSBM ini dilatarbelakangi akan kebutuhan jama'ah. Banyaknya rentenir yang beroperasi di lingkungan sekitar masjid tidak bisa diabaikan. Sementara banyak jama'ah yang terdesak dana untuk kepentingan sekolah anaknya, biaya kesehatannya dan lain-lain yang sering datang ke rentenir. Kenyataan inilah yang mendorong segenap pengurus DKM Baitul Mu'min untuk membentuk sebuah koperasi Syariah yang dinamakan Koperasi Syariah Baitul Mu'min (KSBM). 
..:: Malia: Jurnal Ekonomi Islam Vol. 12 No. 1, Desember 2020 ::..

KSBM beralamat di Jalan Sekehaji RW 15, Komp. Pasir Jati, Desa Jati Endah Kecamatan Cilengkrang Kabupaten Bandung Provinsi Jawa Barat 40616. Telp./HP 085295091348/081214193534

\section{Kegiatan Koperasi Syariah Baitul Mu'min (KSBM)}

Koperasi Syariah Baitul Mu'min melaksanakan beberapa kegiatan dan pelayanan, yaitu:

a. Simpanan anggota yang berupa simpanan pokok, simpanan wajib dan simpanan sukarela.

b. Perniagaan sembako, melayani segenap kebutuhan pokok dari anggota

c. Pembiayaan barang, melayani kepada anggota yang memerlukan barang dengan cara diangsung sesuai kemampuan dan kesepakatan anggota.

d. Unit layanan pulsa, pembayaran listrik, telpon, PBB, PDAM, BPJS, Online Shop, dll.

e. Unit layanan Dapoer KSBM, melayani aqiqah, syukuran, khitanan, pernikahan, dll

f. Penyertaan modal, memberikan peluang kepada anggota yang memiliki usaha, namun ada keterbatasan modal.

g. Unit pelayanan jasa, melayani pelayanan jasa seperti perbaikan pompa air, mesin cuci, pengurusan pajak kendaraan bermotor, rental mobil, pengiriman paket, dll

\section{Analisis Business Model Canvas}

Pada tahap analisis dilakukan pemetaan proses bisnis KSBM yang sudah berjalan dalam konsep Business Model Canvas agar dapat terlihat kelebihan dan kekurangannya. Sehingga akan mudah dilakuka evaluasi dalam rangka perbaikan di kemudian hari. BMC meliputi: Customer Segment (segmentasi pelanggan), Customer Relationship (Hubungan pelanggan), Channel (saluran), Revenue Stream (aliran pendapatan), Value Proposition (proposisi nilai), Key Activities (aktivitas utama), Key Resource (sumber daya utama), Cost Structure (struktur biaya), dan Key Partners (kemitraan utama). Berikut diuraikan hasil analisis BMC untuk KSBM:

\section{a. Customer Segments}

KSBM merupakan salah satu pelopor koperasi syariah yang berada di wilayah Jati Endah Kecamatan Cilengkrang. KSBM akan melayani berbagai lapisan masyarakat yang terdiri dari Anggota KSBM, Jama'ah Baitul Mu'min, warga lingkungan RW 15, dan masyarakat lainnya yang mengetahui keberadaan KSBM. Selain melayani langsung di KSBM, juga memberikan pelayanan berupa menghantarkan pesanan konsumen tanpa dikenai biaya (free delivery order). Dapat disimpulkan bahwa KSBM tergolong mengincar pengguna bertipe mass market.

\section{b. Value Prepositions}

KSBM memberikan berbagai layanan untuk membantu memenuhi kebutuhan konsumen. Pada Tahun 2018 telah menyediakan beberapa produk yaitu simpanan, perniagaan, pembiayaan barang, pinjaman dana, penyertaan modal, pelayanan jasa (aqiqah, cathering, pembayaran pajak kendaraan, perbaikan alat 
elektronik, dan rental mobil, dan payment berupa Pospay (pembayaran listrik, telpon, PBB, PDAM, BPJS, dan online shop). Pada Tahun 2019 diadakan tambahan usaha berupa peningkatan plafon usaha dan KSBM Mart.

\section{c. Channels}

KSBM memiliki sarana interaksi dengan para anggotanya diantaranya adalah dengan dibuatnya WhatsApp Group (WAG) sehingga dapat saling bersilaturrahmi diantra konsumen KSBM, hal ini akan lebih memudahkan penyebaran informasi setiap produk terutama produk terbaru di KSBM. Selain itu KSBM senantiasa melakukan evaluasi melalui musyawarah yang berupa musyawarah pengurus setiap tiga bulan, musyawarah pengurus harian setiap bulan, musyawarah dengan dewan penasihat setiap 3 bulan, dan juga musyawarah akhir tahun. Upaya untuk berkomunikasi juga dapat melalui kegiatan-kegiatan kondisional seperti bazar dan kegiatan pengajian rutin majelis taklim.

\section{d. Customer Relationships}

Cara menjaga hubungan baik dengan konsumen, dengan membuat WAG untuk menginformasikan produk, melakukan pemesanan, komunikasi dan silaturahmi. Selain itu KSBM juga sering melakukan pertemuan melalui even-even tertentu seperti kegiatan majelis ta'lim dan peringatan hari besar Islam. Karena berpusat di masjid juga memudahkan untuk berbagi informasi setiap berkumpul para jama'ah di masjid baik pada waktu-waktu shalat setiap hari maupun kegiatan shalat jum'at. KSBM juga menyediakan layanan saran dan kritik yang dapat disampaikan langsung melalui aplikasi whatsapp kepada pengurus KSBM. KSBM berusaha memberikan pelayanan dan informasi terbaik bagi para konsumennya.

\section{e. Revenue Streams}

KSBM mendapatkan keuntungan dari ikatan kerjasama dengan beberapa mitra melalui pembagian hasil. Selain itu keuntungan dari simpanan dan pinjaman konsumen dengan perjanjian bagi hasil. Keuntungan KSBM didapat pula dari pelayanan jasa berupa biaya administrasi pembayaran (payment) Poslink dan bagi hasil dari kerjasama dengan berbagai reseller. KSBM meraih keuntungan dari penjualan produk yang disediakan di warung KSBM atau KSBM mart.

\section{f. Key Resources}

KSBM mempunyai Sumber daya berupa kepengurusan koperasi yang berjumlah 11 orang, penasihat berjumlah 3 orang, dewan pengawas berjumlah 3 orang dan asset terbesar KSBM adalah anggota aktif KSBM dan jamaah Masjid Baitul Mu'min yang merupakan nasabah dengan jumlah 500 orang di tahun 2019. Tambahan dana bisnis juga didapatkan dari dana-dana yang diberikan oleh para investor yang telah lama berinvestasi di KSBM.

\section{g. Key Activities}

KSBM melayani berbagai kebutuhan masyarakat baik berupa investasi, simpan-pinjam, maupun dalam bidang jasa seperti perbaikan alat elektronik, jasa pembayaran listrik, telpon, PBB, BPJS dan online shop. KSBM juga berusaha 
memperbaiki sistem manajemen dan pelayanan dengan adanya delivery servis gratis, penambahan plafon pinjaman dan juga mendirikan KSBM mart sebagai upaya pengembangan bidang usaha.

\section{h. Key Partnerships}

KSBM memiliki ikatan kerjasama dengan perusahaan lain diantaranya dengan BRI Syariah, bentuk kerjasama dalam bentuk penyimpanan aman dana nasabah. Dalam hal jasa payment KSBM bekerja sama dengan menjadi mitra kantor pos untuk melayani pembayaran PBB, listrik, telpon, BPJS, dll. Sedangkan dalam pembayaran pajak kendaraan, KSBM menjalin mitra dengan Samsat. Selain itu kerjasama juga dijalin dengan beberapa layanan jasa seperti penyedia jasa cathering, aqiqah, dan sewa kendaraan. kerjasama juga dapat berupa konsinyasi yaitu dengan menjualkan barang dengan sistem mendapat keuntungan dari penjualan barang tersebut.

\section{i. Cost Struktur}

Cost struktur menggambarkan keseluruhan biaya yang dikeluarkan untuk mengoperasikan suatu model bisnis. Pengeluaran yang dibutuhkan oleh KSBM yaitu dipergunakan untuk biaya penyusutan aktiva tetap, pembiayaan pulsa, pembiayaan administrasi bank dan biaya-biaya laiinya yang dikeluarkan untuk operasional koperasi. Adapun jumlah biaya yang dikeluarkan KSBM pada tahun 2017 sebesar 13.892.079, sedangkan tahun 2018 mengalami peningkatan menjadi Rp 16.401.526.

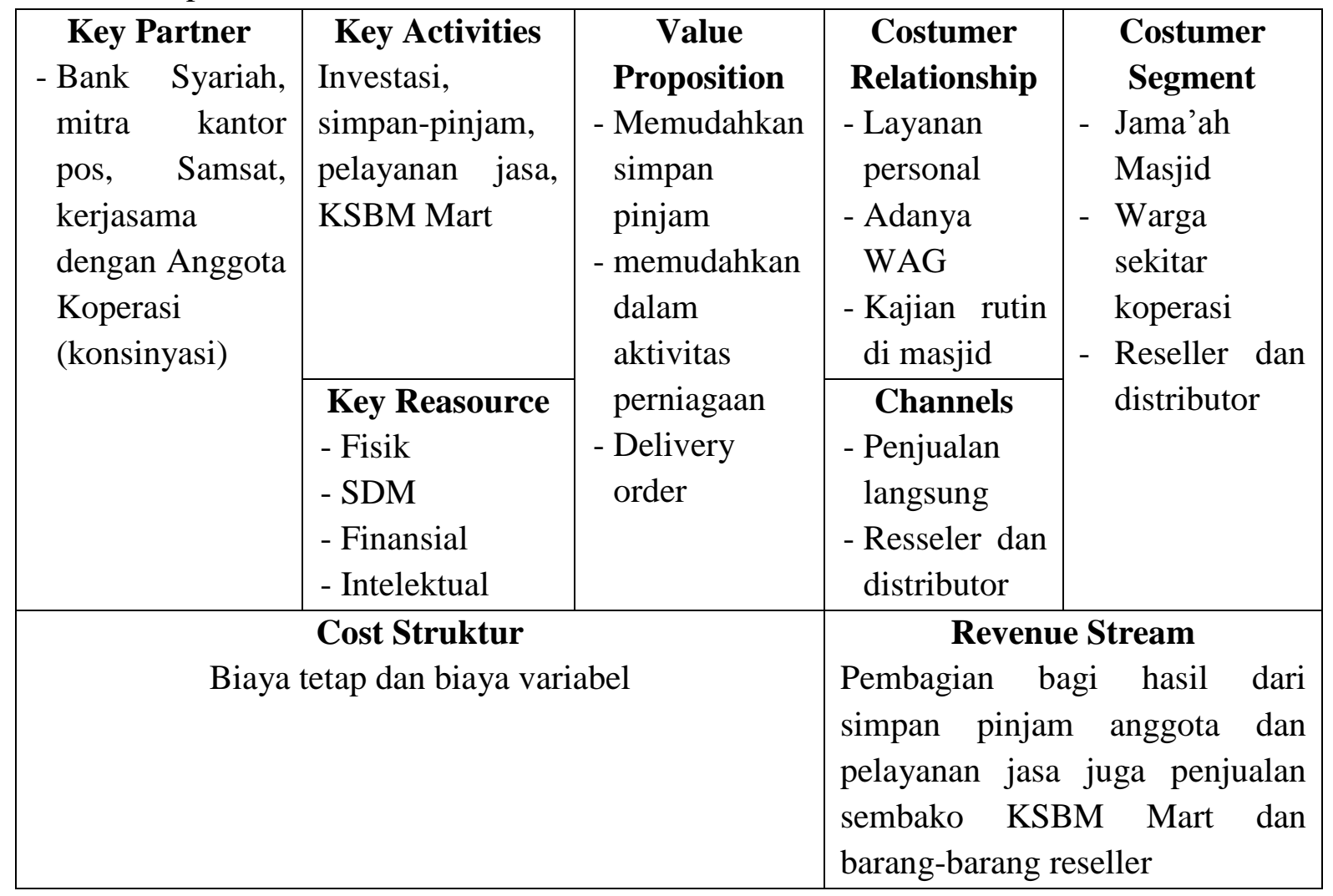

Gambar Business Model Canvas Koperasi KSBM 
Setelah dilakukan analisis maka dapat digambarkan BMC pada KSBM seperti pada gambar di atas. BMC tersebut dapat dijadikan model pengembangan bisnis koperasi syariah di Indonesia mengingat karakteristik koperasi di Indonesia seragam.

\section{E. Kesimpulan}

KSBM merupakan koperasi syariah yang berada di wilayah Jati Endah Kecamatan Cilengkrang. KSBM akan melayani berbagai lapisan masyarakat yang terdiri dari Anggota KSBM, Jama'ah Baitul Mu'min Warga lingkungan RW 15, dan masyarakat lainnya. Selain melayani langsung di KSBM, juga memberikan pelayanan berupa menghantarkan pesanan konsumen tanpa dikenai biaya (free delivery order). KSBM melayani simpanan, perniagaan, pembiayaan barang, pinjaman dana, penyertaan modal, pelayanan jasa. KSBM memiliki sarana interaksi dengan para anggotanya diantaranya adalah dengan dibuatnya WAG sehingga dapat saling bersilaturrahmi di antara konsumen KSBM, hal ini akan lebih memudahkan penyebaran informasi setiap produk terutama produk terbaru di KSBM. KSBM mendapatkan keuntungan dari ikatan kerjasama dengan beberapa mitra, simpanan dan pinjaman konsumen, pelayanan jasa dan penjualan produk yang disediakan di warung KSBM atau KSBM mart.

BMC dapat diterapkan tidak hanya sebagai pengganti business plan, namun juga dapat digunakan untuk pemetaan konsep bisnis dalam hal ini koperasi syariah. Dengan gambaran konsep bisnis yang jelas dalam setiap poin kunci, maka diharapkan BMT ataupun koperasi syariah pada umumnya dapat dengan mudah untuk melakukan pengembangan maupun perbaikan bisnis. 


\section{DAFTAR PUSTAKA}

Anggraini, A. R., \& Oliver, J. (2019). pengertian koperasi syariah. Journal of Chemical Information and Modeling, 53(9), 1689-1699.

Dusuki, A. W., \& Abdullah, N. I. (2007). Maqasid al-Shari`ah, Maslahah, and Corporate Social Responsibility. American Journal of Islamic Social Sciences, 24(1), 25-45.

Efendi, R., \& Bakhri, B. S. (2018). KONSEP KOPERASI BUNG HATTA DALAM PERSPEKTIF EKONOMI SYARIAH. Al-Hikmah: Jurnal Agama Dan Ilmu Pengetahuan, 15(1), 111-135.

Ghulam, Z. (2016). Implementasi Maqashid Syariah Dalam Koperasi Syariah. Iqtishoduna, $7(1), 90-112$.

Herdiana. (2013). Tinjauan Fiqih Muamalah. Journal of Chemical Information and Modeling, 53(9), 1689-1699.

Heri Setiawan. (2016). Pengaruh Kualitas Produk, Kualitas Pelayanan Dan Kepercayaan Terhadap Kepuasan Nasabah Dan Loyalitas Nasabah Dengan Kepuasan Sebagai Variabel Intervening. Journal Of Management, 2(2), 1-17.

Ilyas, R. (2018). Manajemen Permodalan Bank Syariah. BISNIS: Jurnal Bisnis Dan Manajemen Islam, 5(2), 323. https://doi.org/10.21043/bisnis.v5i2.3017

Indonesia, C. (2019). Perang Diskon dan Masa Depan Uang Elektronik. CNN Indonesia. https://www.cnnindonesia.com/ekonomi/20190705122825-92-409395/perang-diskondan-masa-depan-uang-elektronik

Jati, W. R. (2012). Dilema Ekonomi: Pasar Tradisional Versus Liberalisasi Bisnis Ritel Di Indonesia. Jurnal Ekonomi Dan Ilmu Pembangunan (JESP), 4(2), 223-242.

Marwick, T. H. . (2006). Analisis Perbandingan Antara Koperasi Simpan Pinjam Dengan Koperasi Jasa Keuangan Syariah Baitul Maal Wa Tamwil. European Heart Journal, 28(12), 1407-1408.

Nizar, M. (2016). PENGARUH PEMBIAYAAN MUDHARABAH TERHADAP PENINGKATKAN KESEJAHTERAAN PELAKU UMKM (studi kasus BMT Maslahah Capang Pandaan). Jurnal Malia, 7(2), 287-310.

Suparmin, A. (2019). MANAJEMEN RESIKO DALAM PERSPEKTIF ISLAM. El-Arbah: Jurnal Ekonomi, Bisnis Dan Perbankan Syariah, 2(02), 27-47.

Www.Depkop.Go.Id. (2018). Perkembangan Data Usaha Mikro , Kecil , Menengah Dan Usaha Besar Tahun 2017-2018. In Www.Depkop.Go.Id (Vol. 2000, Issue 1). 
..:: Malia: Jurnal Ekonomi Islam Vol. 12 No. 1, Desember 2020 ::.. 